\title{
Canceled conference puts conflicts of interest under scrutiny
}

Can a scientist with financial ties to a company be trusted to give objective advice about issues that directly affect that company's profits?

Experts who successfully lobbied to cancel a government conference dominated by speakers with industry backing say the risk of • commercial interests trumping the public's is too great to take a chance. Even the appearance of conflict, they say, compromises the independence of federal recommendations.

The conference in this case was called by the US National Institutes of Health (NIH) to set guidelines for preventing herpes transmission to newborns.

Three of the five scheduled speakers have received money from GlaxoSmithKline, maker of the blockbuster herpes drug Valtrex. Another speaker, Massachusetts General Hospital obstetrician Laura Riley, is the secretary and treasurer of the American Herpes Foundation, a nonprofit funded by GlaxoSmithKline and Roche, which makes herpes diagnostics. The conference, scheduled for 21 February, was expected to recommend mandatory screening of expectant mothers for herpes.
"It's one thing for a professional society to have guideline writers who are conflicted, but it's another when it's the government," says Eric Topol, director of the Scripps Translational Science Institute in La Jolla, California. "It's the job of the NIH to find those who are not conflicted."

Once news of the conference got out, the Washington, DC-based advocacy group Center for Science in the Public Interest and 43 scientists and public health experts, including Topol and Lancet editor-in-chief Richard Horton, protested the panelists' financial conflicts in a letter to the $\mathrm{NIH}$. The letter described the industry-weighted bias of guidelines drafted by other NIH panels for treating high blood pressure, high cholesterol and HIV/AIDS.

"They're telling the whole medical community, with a government stamp of approval, that you should use this. The recommendations may be fine, but the perception is that they could be influenced," says Topol.

The NIH canceled the conference on 18 January, citing in a letter distributed to invited scientists "concern that the current misperceptions could not be resolved prior to the scheduled meeting date." Agency officials declined to be interviewed for this article.

In a field of research that receives little public funding, many scientists-including opponents of expanded screening — are funded or paid by pharmaceutical companies to speak at conferences.

But that's not the issue, critics say.

"We weren't taking issue with their careers," says Adam Urato, a University of South Florida obstetrician. "Our issue was, do we want experts paid by industry to be writing and dictating the clinical practice guidelines?"

University of Washington obstetrician Zane Brown, one of the speakers, told Nature Medicine that "the connection with big pharma is not relevant." But even he says the drafting of new guidelines would have been better served had the NIH called on speakers without industry ties.

"I would propose to have the conference [in 2009] after the patent expires on the antiviral agent," Brown says. "That way, no one will be able to claim that there are financial interests in the recommendation."

Brandon Keim, New York

\section{AIDS gel's failure calls prevention approach into question}

AIDS researchers delivered a stunning blow to prevention efforts for the disease, announcing on 31 January that the microbicide Ushercell, a promising prevention tool, instead increases the rate of infection with HIV.

Ushercell's failure, the second time a microbicide has met this unwelcome fate, has come as a bigger shock to the scientists themselves-and illustrates the complex challenges scientists encounter in the final stages of microbicide research.

In earlier trials, Ushercell seemed both safe and effective. But in a large phase 3 trial of 1,333 sexually active women in South Africa, Benin, Uganda and India, the researchers discovered that more women using the gel had become infected with HIV than those using the placebo, and swiftly put an early end to the trial.

"We have no idea what happened, we are totally baffled," says Roshini Govinden, lead researcher for the trial's South African arm.

Ushercell, a vaginal gel aimed at protecting women against sexually contracted HIV, acts as an entry inhibitor: its active ingredient, cellulose sulfate, binds to the viral envelope proteins and prevents them from fusing with host cells.

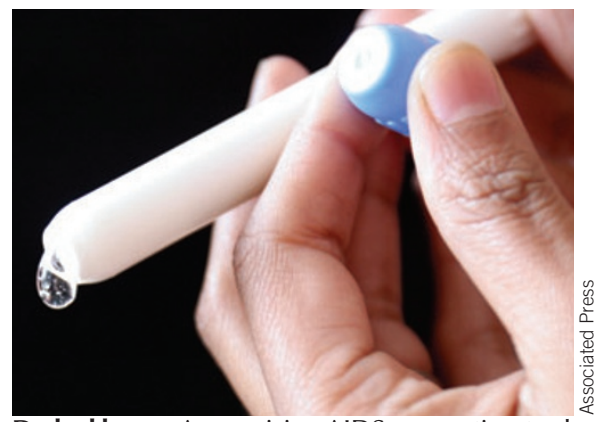

Dashed hopes: A promising AIDS prevention tool has proven to increase the risk of HIV infection.

In 2000, trial results of the detergent nonoxynol-9 also showed that product increased the risk of sexually transmitted HIV infection. Several other microbicides have been found in phase 3 trials to be ineffective.

Trials of microbicides pose unique challenges for scientists. In many African cultures, men prefer dry sex, making the women in the trial reluctant to use the gels consistently. As part of the trials, researchers are also required to counsel the participants about condom use, leading some women to use condoms more often than the gel being tested. Counseling also generally lowers the rate of new infections, making it difficult to find a statistical difference between the microbicide and placebo arms.

All these factors, combined with treatment for sexually transmitted infections, make microbicide trials large and expensive. For instance, a phase 3 trial of the Carraguard, a seaweed extract that acts as an entry inhibitor, enrolled nearly 7,000 participants to measure a 33\% decrease in HIV incidence.

Neither Carraguard nor the two others still in phase 3 trials are expected to be $100 \%$ effective. Ushercell's failure has bolstered skepticism about microbicides generally.

"I'm not at all surprised that Ushercell showed no activity," says John Moore, an immunologist at Cornell University. The trial's outcome, Moore says, indicates the usefulness of monkey models "to weed out the less useful concepts before they get as far as Ushercell did."

CONRAD, the US-based research organization that sponsored the trials, has thus far declined to explain the unexpected result. Detailed results are expected by the summer, says Annette Larkin, CONRAD's spokesperson.

Natasha Bolognesi, Cape Town 